looked in the drug addiction film "The Man with the Golden Arm."

Then at my outpatient clinic another patient suffering from neurotic depression told me how very ill she felt after stoppng her regimen of phenelzine and haloperidol to go on to lorazepam. The lorazepam made her excessively drowsy and she stopped it after a day or so but then she felt depressed and irritable and also described this feeling of cold and shivering.

This last symptom is quite reminiscent of the "cold turkey" reaction to the withdrawal of narcotics from the habituated, and the reaction followed so swiftly the discontinuation of the drug that I wonder if it might not represent a genuine physical response to deprival of the drug rather than a purely psychological one or the return of the depression. The medical adviser to the manufacturers tells me that no such withdrawal symptoms have previously been reported but I wonder if any of your readers can record similar experiences? - I am, etc.,

The London Hospital

BRICE PITT

(St. Clement's)
London E.3

\section{Malaria in the United Kingdom}

SIR,-In your epidemiological report (5 January, p. 43) you mention 84 cases of malaria in immigrants to the U.K. in 1972. The adult populations of countries where malaria is endemic are generally considered to be immune to malaria in the sense that they do not suffer overt attacks of the disease.

It would be valuable to know if there is any record of the proportion of immigrants in whom malaria was considered to be the cause of their illness rather than simply a concomitant finding, the number of adults, and whether any factors were found, such as acute infections or steroid therapy, which might have been responsible for a temporary lowering of resistance to malaria.-I am, etc.,

Department of Medicine,

Ahmadu Bello University

Zaria, Nigeria

\section{Intensive Care: Allocation of Resources}

SIR,-Your issue of 23 Manch (p. 567) contains an article by Dr. K. Astvad and others on the effect on mortality from cardiac infarction of the establishment of an (intensive) coronary care unit. Health Trends for February 1974 includes a report by Dr. Eva Alberman on stillbinths and neonatal mortality in England and Wales by birth weight during 1953-71.

The first article suggests that intensive care makes little difference to the ovenall mortality of patients with coronary heart disease; the second makes it clear that provision of adequate neonatal care, including intensive care, in maternity hospitals makes a great deal of difference to mortality in newborn infants, as it has also done to morbidity. ${ }^{2}$

The moral as regards allocation of resources is obvious, but it is not obvious that it has been drawn, nor that it will be while the British Paediatric Association emains a poor relative of the royal colleges with no direct representation, for in stance, on the Central Health Services Council and similar bodies.-I am, etc.,

\section{J. A. Davis}

University Department of Child Health,

t. Mary's Hospital,

anchester

Alberman, E., Health Trends, 1974, 6, 14 Stewart, A., in Perinatal Medicine, ed. H. Bosand J. Sistek, p. 181 . Bern, Huber, 1973. Lancet, 1972, 1, 437 .

Thromboembolism and Oral Contraceptives

SIR,-Your leading article (9 February, p. 213) suggests a difference in the possibly thrombogenic effect of unnatural oestrogenic compounds and natural oestrogens.

A normal content of fibrinolytic activators in the vessel walls is important for counteracting thrombosis. ${ }^{1}$ In an earlier investigation we found that ethinyloestradiol in a large dose $(250 \mu \mathrm{g}$ daily for 10 days $)$ depressed the fibrinolytic activity in the venous vessel wall in post menopausa women about to be operated upon for uterine prolapse. ${ }^{2}$ We now have given 17 beta-oestradiol to a similar group of 16 women in a biologically equivalent dose (10 mg daily for 10 days). Biopsy specimens of superficial veins were obtained be fore and during the last day of treatment and were examined histochemically fo their content of fibrinolytic activators. In contrast with the findings during treatmen with ethinyloestradiol, no significant depression of the fibrinolytic activity was found, which is in accordance with your editorial suggestions.-We are, etc.

B. ÅsTEDT

Coagulation Laboratory,

S. JEPPSSON

Allmänna, Sjukhuset,

1 Isacson, S., and Nilsson, I. M., Acta Chirurgica 2 Scandinavica, 1972, 138, 313 .

Astedt, B., Acta Obstetricia et Gynecologica Scan dinavica, 1971, 50, 279.

\section{Skin Reactions to Practolol}

SIR,-Since the report by Rowland and Stevenson ${ }^{1}$ in 1972 of a patient with exfoliative dermatitis who was taking practolol we have been concerned at the increasing number of patients we have seen who have developed a rash caused by this drug. Although a minority of patients presented with either an eczematous eruption or exfoliative dermatitis, the majority have presented with a distinctive psoriasiform eruption, further details of which will be the subject of a full communication.

We have been struck by the uniformity of this type of eruption, particularly in its distribution on the hands and bony prominences, the main features of which are scaling and thickening of the skin of the palms, soles, and sides of digits with atypical psoriasis-like plaques over the knees. The remainder of the rash is widely scattered over the body, being red and characterized by marginated scaling. In our opinion the clinical features produce an easily recognizable diagnostic picture.

These patients have been taking practolol for periods ranging from three weeks up to two years, with a mean duration of treatment of 10 months, before the onset of the rash. As this drug has now been available for over two years this latent period before the onset of the rash may be one explanation for the apparent increased frequency of the practolol-induced rashes that is our impresson at present. We therefore consider it timely to draw the attention of the medical profession to this entity.-We are, etc.

Department of Dermatology,

ROBIN FELIX Royal Victoria Hospital

Dryburn Hospital,

F. A. IVE Durham Rowland, M. G. M., and Stevenson, C. J.,
Lancet, 1972, 1, 1130.

\section{Drugs Affecting Oral Contraceptives}

SIR,-Ever since oral contraceptives were introduced, their efficacy has almost been taken for granted. By both the doctor and the patient they have been regarded as being almost infallible. In the very rare cases where a pregnancy occurred the blame was first laid against the patient for having forgotten the pill and then only rather grudgingly against the pill. Recent publications have, however, started to accumulate to show that neither the patient nor the pill may be at fault. It may in fact be that the patient is taking other medicines and that these may be preventing the pill from producing the proper contraceptive effect. This effect appears to act mainly against the oestrogen content and may explain the strange finding that the average age of the patients who became pregnant while taking the pill was $35^{1}$. This was found to be occurring predominantly on sequentialtype oral contraceptives.

The most marked effect on oral contraceptives would appear to come from the antibiotic rifampicin. This antibiotic is one of the recently introduced antituberculosis drugs and it has gained wide usage in many countries as it is very effective and easy to administer. Unfortunately, since it is given to ambulant patients many of these may also be to ambulant patients many of these may also be taking oral contraceptives to prevent unwanted pregnancies during their treatment period. The
first indication of this interaction came from Reimers et al., ${ }^{2}$ who found that of 88 patients with Reimers et al., ${ }^{2}$ who found that of 88 patients with
pulmonary tuberculosis who were taking oral pulmonary tuberculosis who were taking oral
contraceptives in addition to rifampicin, $75 \%$ contraceptives in addition to rifampicin, $75 \%$
suffered from cycle disturbances and five became pregnant, whereas in another group, who received streptomycin, only $4 \%$ showed any cycle irregularity and there were no pregnancies.

Though other workers ${ }^{3}$ found no cycle disturbances or pill failure, it was felt by Reimers that
rifampicin might influence the biogenesis and rifampicin might influence the biogenesis and
metabolism of the oestrogens and that this might metabolism of the oestrogens and that this might
lead to failure of action. Other antibiotics have also been shown to affect oestrogen metabolism, for ampicillin given to healthy mothers in the latter weeks of pregancy decreases the urinary oestriol levels by as much as $69 \%$ of the pretreatment level. ${ }^{4}$ It was felt that ampicillin also could give rise to unexpected complications with oral contraceptives by affecting the enterohepatic circulation of the oestrogens. This type of work has been confirmed by other workers. ${ }^{5}$

The second most common therapeutic group to affect the mechanism of action of oral contraceptives are the barbiturates. This could have been expected, as it was reported in 1968 by Levin $^{8}$ that in animals chronic treatment with phenobarbitone could reduce the uterotropic effect of oestrogen and progestogens. Other workers ${ }^{9}$ reported that barbiturates stimulate the metabolism, by enhancing the hydroxylation, of all steroids, and it was confirmed ${ }^{10}$ in vitro and in vivo in animals that the conversion of mestranol to erthinyloestradiol could be increased as much as three times by pretreatment with barbiturates. 